\title{
Understanding the Ego Network Structure of Followers in Social Marketplaces: Structural Capital or Liability?
}

\author{
Shan Wang \\ Department of Finance and Management Science \\ The University of Saskatchewan \\ Email:wang@edwards.usask.ca \\ Fang Wang \\ Lazaridis School of Business \& Economics \\ Wilfrid Laurier University \\ Email: fwang@wlu.ca
}

\begin{abstract}
In social marketplaces, follower networks are one of the most important digital assets that online sellers have. The existing literature repeatedly reports the strong positive effect of the number of followers on seller performance. However, to date, limited research has been done to understand the ego network structure of sellers' follower networks. The structures of social networks may characterize different resources that sellers can leverage to enhance their sales performance. This research studies three network structural properties, including network density, network fragmentation, and network centralization, and their impacts on seller performance. A panel data of 1,150 sellers were collected and analyzed. The results show that network density and centralization are negatively related to seller performance. This suggests that sellers in social marketplaces should avoid highly dense and centralized networks when they build and maintain their follower networks.
\end{abstract}

\section{Introduction}

Online community, aiming to enhance user experience through supporting user interactions and user-generated content [1], is a popular design feature of e-commerce marketplaces [2, 3]. Examples include online product communities for users with similar product interests, such as those on Etsy [4] and Instagram. Online product communities add value to users by facilitating them to collect products of their interests, learn about new products from other users, and share their collections in the communities [4]. Via social networking, users achieve not only the benefit of informed online shopping but also social fun $[5,6]$. Ecommerce sellers commonly participate in online product communities and derive business value through interacting with and sharing content to other users [7]. Small and individual sellers are especially likely to benefit from participating in such communities because they have a high reliance on online social networking to attract customers due to limited marketing budgets.

A seller can build and maintain its personal networks (i.e., ego network) by attracting others to follow him/her or following other users in the communities. An ego network is defined by a seller's direct connections (i.e., alters) and the relationships among alters. This research focuses on sellers' follower ego networks. In online communities, a seller's follower ego network consists of the ego (i.e. the focal seller), the followers (i.e., alters or fans) of the ego, and the connections among the followers [8]. Such an ego network of followers can help a seller curate content and maintain relationships with potential customers, thus is considered valuable social capital for sellers $[4,9]$.

Prior research has consistently confirmed the importance of follower networks in that the number of followers positively contributes to seller performance $[4,7,9,10]$. However, the network theory suggests that social capital available for an ego (i.e., a seller) is determined not only by the number of alters (i.e., followers) but more importantly by the structure of the ego network $[11,12]$. Network structural properties such as density and centralization determine the resources available for ego's leverage. For example, a dense network may indicate that the ego seller is followed by a coherent user group, which may affect its sales performance. The effect of the structural properties of the follower ego network on seller performance has not been studied in social commerce.

Based on the social network literature, this research studies the important ego network structural properties such as density, fragmentation, and centralization on the sales performance of sellers in social marketplaces (i.e., e-commerce marketplaces that are rich in social networking functionalities). We tracked and analyzed the e-commerce and social networking activities of 1,150 e-commerce sellers in Etsy, a social marketplace specializing in art and craft products, for 13 months, to provide empirical evidence of the impact of these structural properties. This research contributes to social commerce research by enhancing our understanding of the performance 
implications of the structural properties of follower ego networks in social marketplaces.

\section{Literature review}

Social networking is a prominent feature of online social marketplaces, resulting in the formation of social networks among users. Social networks embed the structural capital of the egos and their potential access to resources [13], and can both enable or constrain their behavior and performance. For example, Kelvin's research [14] found that once the Facebook social network is made visible in the Yelp community, users change their behavior by reducing their content sharing in Yelp. Studying the network characteristics can reveal the mechanisms of such enabling or constraining effects.

Social networking is a central theme in social commerce research, which focus has been on buyers' social networking behavior and effect. A large body of research has studied how social networking changes buyers' shopping behaviors and purchase intentions [5, $15,16]$. For example, friends interacting on social networks are subject to the social influence of each other, affecting their purchase and non-purchase activities [16]; social networking enables buyers' social learning via various types of network interactions and affects their purchase intention [5].

Comparatively, less attention is given to understanding sellers' networking behavior and effect. The few studies on this stream of research focus on degree centrality and employed simple social media metrics, such as the number of followers, as an indicator of social capital of ego network [4, 9, 10, 17]. The structural properties of the ego network and their effects have not been studied. For example, Susarla, Oh [17] studied the in-degree and out-degree centralities of YouTubers (i.e., numbers of followers and followees, respectively) in two networks, the subscriber network and the friend's network, and how such networks positions affect YouTubers' performance. Stephen and Toubia [7] studied more network position indicators of seller networks such as in-degree centralities, out-degree centralities, authority (in-eigenvector centrality), hub (out-eigenvector centrality), in-proximity centrality and out-proximity centrality, and their impacts on seller commissions in an e-commerce website. But their research mostly focuses on the centrality indexes rather than the structural properties of ego networks.

A robust finding of these studies is that the indegree centrality positively relates to seller performance [4, 9, 10, 17]. Zifla and Wattal [4] explain that the number of followers indicates the status that a seller achieves in a social marketplace and signals the quality of the seller's store and its products. Research has also contrasted the in-degree centrality and the outdegree centrality. Hofer and Aubert [18] found that the number of followers in Twitter is associated with bonding social capital, whereas the number of followers influences bridging social capital. Social capital consists of all the resources owned by an individual because of his or her social contacts. Bonding social capital is the social capital that a person often found in dense networks of like-minded individuals such as close friends and family. Bonding social capital normally consists of emotional support, access to scarce resources within a close-knit network, and the ability to mobilize solidarity. Bridging social capital occurs by the formation of rather weak ties between people from different networks. These ties may be useful for reasons such as for finding a job or accessing diverse sources of information. Hofer and Aubert [18] further commented that the benefits of social capital gained through increasing the numbers of followers and followees are only to a certain point. Network users often have too many followers and followees [18]. The limit of benefiting from the increase of the follower number calls for an in-depth understanding of the structural characteristics of follower networks to study the nuanced structural capital and social resources owned by an ego.

The prior literature has not examined in depth the structural properties of sellers' ego networks in social marketplaces. A relevant work by Yu, Tao [19] studied the social network of sellers on Taobao, a famous ecommerce marketplace in China, and suggested that network characteristics such as family ties, structural holes, and tie strength affect seller performance by enhancing their legitimacy in the marketplace. The offline social networks studied by Yu, Tao [19] are distinct from the common online ego network of sellers that are formed based on shared product interests. Studying the structural properties of sellers' ego networks in social marketplaces can provide significant insights into the value implications of social networks in seller performance and their optimal networking behavior.

\section{Theory and hypotheses}

Social network theory provides useful guidance for us to look for meaningful structural properties of follower ego networks. The ego network properties that are particularly relevant to our study include density, fragmentation, and centralization. 


\subsection{Ego network density}

Density is a measure of the degree of connectedness of alters in a network. Network density is related to the availability of social support and the presence of a strong social safety net [20]. High density has been conceptualized as a component of bonding social capital, or close-knit ties to homogeneous others which foster shared social norms and cooperation [20].

In organizational networks, network density facilitates the formation of trust among network members, a reputation mechanism, and coalitions to constrain opportunistic behaviors of members [21, 22]. Network density enhances absorptive capacity, which is a desired property when organization members collaborate on research and development that involves complicated, distant knowledge sharing and transfer $[21,23,24]$. However, network density also entails network closure [25], limiting the potential for novel creation by limiting the access to novel external knowledge and sanctioning network members for their creation that does not fit group norms.

In social marketplaces, the density of a seller's follower network has both positive and negative implications. A dense ego network of sellers with close connections among followers implies that the homogeneity of followers in their product tastes and in their information $[18,21]$. Such an ego network can benefit sellers' sales performance through quick product information diffusion and word-of-mouth recommendations.

However, there are also backlashes for sellers if their ego network is dense. A dense network indicates more communications among followers. As a result, they accrue market knowledge as a group, are savvier in knowing competing products in the market and homogenous in their choice $[4,21]$. This may be beneficial to a few market winners, but to general sellers, it leads to more competition among substitute products and easy switch to competitors. The coherent choice of products may be particularly detrimental to sellers who compete based on variety and diversity since products with different styles run high risks of being not appreciated. In e-commerce, variety is an important strategy due to the virtual shelf and low cost of channels. Maintaining a coherent, dense network may limit a seller's sales growth potentials. Based on the above argument, we propose two competing hypotheses about the effect of network density on a seller's e-commerce performance:

Hypothesis 1(a): The density of the follower ego network is positively related to the ego seller's sales performance.
Hypothesis 1(b): The density of the follower ego network is negatively related to the ego seller's sales performance.

\subsection{Ego network fragmentation}

Network fragmentation measures the extent to which an ego's network has separate groups of alters that have no connection to each other except through the ego [20]. Network fragmentation can be measured by component ratio. A component is a maximal connected subnetwork in a network in which every node can reach every other node through some paths. The more components, the more fragmented the network. Since large networks normally have more components, component ratios are normally used to measure the extent of network fragmentation.

The organizational network research suggests that an ego with a fragmented network can enjoy the bridging benefit of connecting different components that otherwise are unable to communicate with each other. Bridging different groups enable access to different information and resources [24]. An ego also enjoys the benefit of "limited liability" since unsavory information about the ego surfacing in one component will not be diffused to other components. However, fragmentation also creates problems when the need from the ego network members requires coordination among members [20].

In social marketplaces, fragmentation implicates diverse and distinct follower groups that do not connect. This can have mixed impacts on sellers' performance. On the one hand, it can potentially benefit a seller by providing the opportunity to tap into different user groups with diverse product interests. On the other hand, it implies that a seller needs to develop the internal capabilities to cater to a large number of distinct segments, which can be challenging to social commerce sellers who are normally small and mediumsized enterprises. Therefore, we hypotheses the two competing effects of ego network fragmentation on seller's sales performance in social commerce:

Hypothesis 2(a): The fragmentation of the follower ego network is positively related to the ego seller's sales performance.

Hypothesis 2(b): The fragmentation of the follower ego network is negatively related to the ego seller's sales performance. 


\subsection{Ego network centralization}

Network centralization refers to the extent to which a network is dominated by a single node. A maximally centralized network is a star network in which the node at the center of the network has ties to all other nodes and no other ties exist. A circle network in which every node is connected to the node before and after it and no other ties exist, is a non-centralized network [26]. Centralization measures the extent of dispersion of the centralities of the nodes in a network, with ego excluded. Centralized networks are common network structures in online communities. Johnson, Faraj [27] studied the social mechanisms that give rise to network centralization: preferential attachment (where new entrants favor connections with already popular participants), least efforts, direct reciprocity, and indirect reciprocity. Their empirical findings suggest that the formation of network centralization is not dominated by a single mechanism but the results of the blend of multiple mechanisms.

In organizational network research, centralized networks affect information diffusion and work performance through the mechanisms of social influence and collective learning mechanisms [28]. High centralized networks give a few centrally located individuals disproportionate levels of social influence [29]. On the positive side, the centrally located individuals in the network can leverage their influence to coordinate the work among group members, enhancing work efficiency. Centralized networks can also achieve higher learning efficiency by aggregating knowledge to a few centralized locations and make them available for network members. On the negative side, a negative social influence effect may dominate as the structure could amplify the influence of a few centrally located individuals in the network [28, 29]. It can be detrimental to the group members' performance when the centralized actors exert their social influence to serve their own interests at the costs of other members. Centralized networks may also impede learning in the network as the knowledge repository and flow are controlled by the central actors.

In social marketplaces, network centralization of the follower ego network can also have mixed impacts on seller performance. High network centralization implies a few big influencers in the seller's follower ego network. These big influencers may create network dynamics and uncertainties for the ego sellers. On the one hand, the influencers' connection to the ego signals the endorsement of products from prominent users in the network, which enhances other users' confidence in the seller [33]. On the other hand, the influencers may direct users to other sellers that the influencers follow. The influencers aggregate products and shops of their interests and likes in their collection and this central repository facilitate the product comparisons of their followers. What makes it worse is that the products and shops collected by the influencers are likely to be those similar to the ego seller since the influencers' collection is determined by their personal tastes, which can be homogeneous [4]. In this sense, the existence of influencers enhances the competition facing the ego sellers. Based on the above argument, we propose two competing hypotheses about the effect of network centralization on sellers' e-commerce performance: Hypothesis 3(a): The centralization of the follower ego network is positively related to the ego seller's sales performance.

Hypothesis 3(b): The centralization of the follower ego network is negatively related to the ego seller's sales performance.

\section{Research methodology}

\subsection{Data collection}

We collected data from Etsy, a social commerce marketplace for crafts and vintage and creative products. The mission of the Etsy platform is to support the interactions of handmade product lovers and also support the sales of the products if the users wish to sell their products. Users of the platform can open e-stores on Etsy to sell their products. Sellers on the Etsy platform are mainly individual sellers. According to Etsy.com [32], "Etsy sellers are techenabled microbusinesses pursuing their entrepreneurial venture on their own terms, and with their own style. Most Etsy sellers (80\%) are businesses of one, and $97 \%$ operate their creative business from their homes". Etsy also offers users (both buyers and sellers) an online community to share their interests in products and shops. Users can build their profiles, add their favorite products and shops to their boards, and use the social network service module to follow others or check who is following them.

Figure 1 shows a screenshot of a sample user profile in this community. As we can see from the figure, this user followed 66 users, has 96 followers, and favorited 97 items. Other users can browse his/her profile. If one wishes to follow this user, he/she can click "+follow" button. By following this user, the followers can receive updates of the user's favorite items and new products launched. Since this user is also an Etsy seller, its e-store link in the Etsy marketplace is provided on the community profile page. Interested followers can click the link to access the seller's e-store to browse more products or make purchases. Followers are potential users who share 
similar product interests as the seller and are interested in the seller's products. A seller stands high chances to convert followers in the online product community into customers and retain them for future repeated purchases.

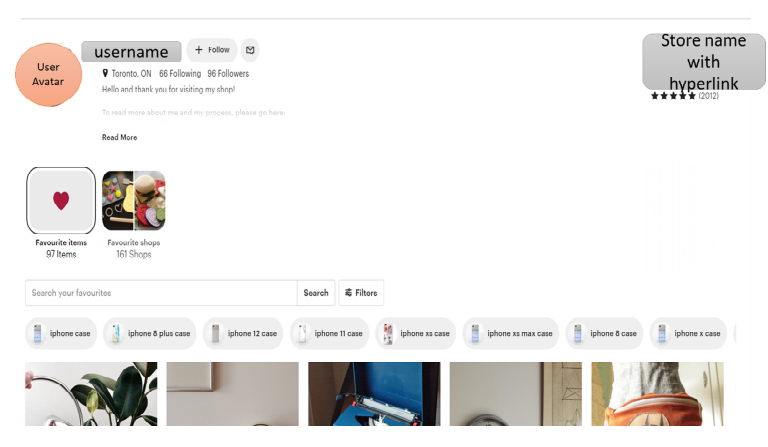

Figure 1 A sample user profile page on Etsy's online product community

We developed a Java script to scrape data on sellers' e-commerce operations and online community activities on Etsy. We randomly selected 1,150 sellers and scraped their sales, store age, and store rating data from their store homepages on Etsy. We scraped each seller's community activity data, including their usernames, number of products they favorite, number of followers, and number of followees. To construct each seller's follower ego network, we also downloaded information on their followers (i.e., alters) via Etsy API, including their usernames. To understand whether the alters (i.e., the ego's direct followers) are connected, we went one step further to download the followers' followers and followees. If a follower's follower or followee happens to be one of the ego's direct followers, the two followers are connected. We collected the above data monthly for 13 months starting from August 2019. Since some sellers' information was not available during the monthly data collection period, the dataset is an unbalanced panel dataset.

\subsection{Measurement}

The dependent variable, sales performance, is measured by the cumulative sales of Etsy sellers. The same measurement is used in Zifla and Wattal [4] when they study the impacts of Etsy followers on sales. The sales figure is log-transformed since it is highly skewed.
The measurements for three main independent variables are adopted from the social network literature $[20,26]$ (See Table 1). Density is measured by the number of ties among alters $(T)$ divided by $N(N-1)$, where $N$ denotes the number of nodes in the ego network (ego excluded) [20]. The value of the density measure ranges from 0 to 1 with 1 indicating a fully connected network. The fragmentation is measured by component ratio [20], calculated as $(\omega-1) /(N-1)$, where $\omega$ denotes the number of components and $\mathrm{N}$ denotes the number of nodes in the ego network (ego excluded). Its value ranges from 0 to 1 with 1 indicating a highly fragmented network. A highly fragmented network may have many small components or isolates that are unreachable by any other nodes. Centralization is calculated as $\sum_{i=1}^{N}\left[C^{*}-C_{i}\right] /$ $\max \sum_{i=1}^{N}\left[C^{*}-C_{i}\right]$, where $C_{i}$ is a node's in-degree centrality index and $C^{*}$ is the largest value of the indegree centrality index that occurs across the $\mathrm{N}$ nodes in the network. It is the sum of the differences between the own centrality of each node and the maximum node centrality in the network, divided by the theoretical maximum possible sum of differences in node centrality, where the differences are taken pairwise between nodes [30]. According to Wasserman and Faust [30], the denominator is a theoretical quantity. It is calculated by considering all possible networks with a fixed number of nodes $\mathrm{N}$, and determining how large the sum of differences can actually be. In-degree centrality is used in the calculation of centralization since we are mainly interested in the follower network.

Table 1 Measurements of main network variables

\begin{tabular}{|c|c|}
\hline $\begin{array}{c}\text { Network } \\
\text { variables }\end{array}$ & \multicolumn{1}{|c|}{ Measurements } \\
\hline $\begin{array}{c}\text { Network } \\
\text { density }\end{array}$ & $\begin{array}{l}\text { T: number of directed ties } \\
\text { N: number of nodes in the ego } \\
\text { network (ego excluded) }\end{array}$ \\
\hline $\begin{array}{c}\text { Network } \\
\text { Component } \\
\text { Ratio }\end{array}$ & $\begin{array}{c}\text { ComponentRatio }=\frac{T}{(N-1)} \\
\text { N: number of components } \\
\text { network (ego excluded) }\end{array}$ \\
\hline $\begin{array}{c}\text { Network } \\
\text { centralization }\end{array}$ & Centralization $=$ \\
\hline
\end{tabular}




\begin{tabular}{|l|l|}
\hline \multicolumn{1}{|c|}{$\frac{\sum_{i=1}^{N}\left[C^{*}-C_{i}\right]}{\max \sum_{i=1}^{N}\left[C^{*}-C_{i}\right]}$} \\
$C_{i}:$ a node's in-degree centrality \\
$C^{*}:$ the largest value of the in- \\
degree centrality that occurs across \\
the N nodes in the network.
\end{tabular}

We control the following e-commerce variables in the study: tenure (i.e., store age in the number of years in the marketplace), average rating of the sellers, the total number of products of a store (log-transformed), the median price of products of a store (logtransformed), and the total number of external marketing channels such as Facebook and Instagram. We also control two social networking variables: the number of followers and the number of followees. Both variables measure the size of the sellers' ego network and are log-transformed.

Table 2 shows the descriptive statistics of the sample. As we can see, for most Etsy sellers, their follower ego network is not well connected, highly fragmented, and distributed, as the mean density, ComponentRatio and centralization of the sellers in the sample are $0.01,0.71$, and 0.06 , respectively.

\section{Table 2 Descriptive statistics of main network variables}

\begin{tabular}{|l|c|l|l|l|l|}
\hline \multicolumn{1}{|c|}{ Variable } & \multicolumn{1}{c|}{ N } & Mean & SD & Min & Max \\
\hline Log_Sales & 14372 & 7.42 & 1.95 & 2.48 & 13.08 \\
\hline Tenure & 14372 & 6.37 & 2.68 & 2.00 & 14.00 \\
\hline AverageRating & 14372 & 4.64 & 1.12 & 0.00 & 5.00 \\
\hline Log_NumReview & 14372 & 5.67 & 2.15 & 0.00 & 11.83 \\
\hline $\begin{array}{l}\text { Log_NumOfProd } \\
\text { uct }\end{array}$ & 14372 & 4.17 & 2.18 & 0.00 & 10.15 \\
\hline $\begin{array}{l}\text { Log_MedianPric } \\
\text { e }\end{array}$ & 14372 & 3.25 & 1.15 & 0.31 & 8.01 \\
\hline $\begin{array}{l}\text { Log_NumOfCha } \\
\text { nnel }\end{array}$ & 14372 & 0.84 & 0.70 & 0.00 & 3.04 \\
\hline $\begin{array}{l}\text { Log_NumOfFoll } \\
\text { owee }\end{array}$ & 14372 & 2.62 & 2.31 & 0.00 & 6.99 \\
\hline $\begin{array}{l}\text { Log_NumOfFoll } \\
\text { ower }\end{array}$ & 14372 & 3.88 & 1.86 & 0.00 & 8.62 \\
\hline Density & 14372 & 0.01 & 0.02 & 0.00 & 0.50 \\
\hline ComponentRatio & 14372 & 0.71 & 0.33 & 0.00 & 1.00 \\
\hline Centralization & 14372 & 0.06 & 0.08 & 0.00 & 0.64 \\
\hline
\end{tabular}

A challenge in studying social networks is that social network ties are relatively stable, which invalidates a longitudinal analysis of network properties. We calculate the percentage changes of the three network properties, Density, ComponentRatio, and Centralization, over 13 months. Figure 2 shows the line charts of the percentage changes. Density percentage changes range from $-0.365 \%$ to $1.461 \%$, ComponentRatio percentage changes ranges from $0.001 \%$ to $0.299 \%$, and Centralization percentage changes range from $-0.004 \%$ to $1.378 \%$. The charts demonstrate reasonable variabilities of the three network properties that make the longitudinal analysis of the impacts of network properties on sales feasible.
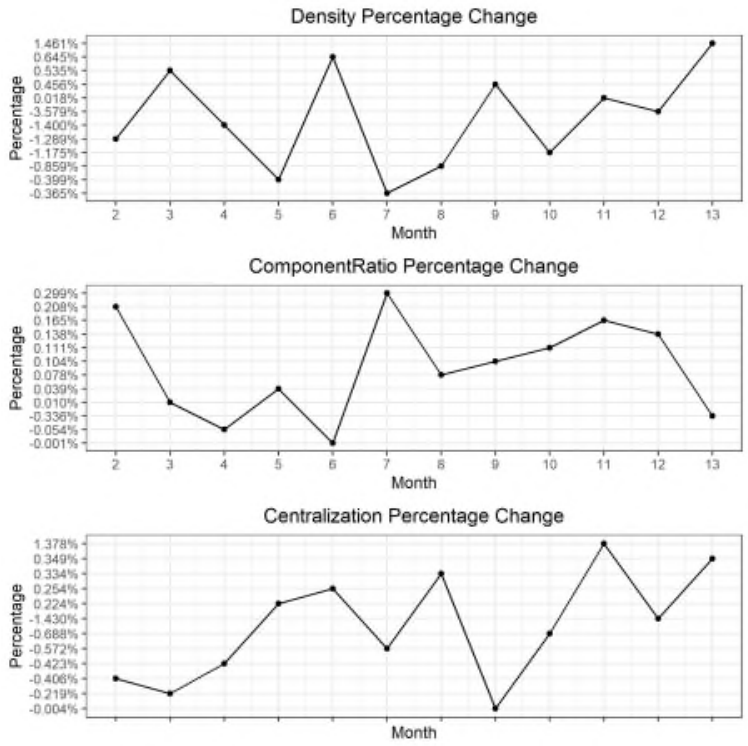

Figure 2 Variability of network properties

\section{Empirical model and results}

\subsection{Empirical model}

We use a linear fixed effects model to test the hypotheses. The following shows the regression model. The dependent variable is Log_Sales and the independent variables include three network variables (Density, Fragmentation, and Centralization) and the control variables, as explained in the measurement. All VIFs among variables are below 3 with one exception (4.29 for Log NumOfFollowers), indicating low collinearity of the model. 


$$
\begin{aligned}
\text { Log_Sales }_{i, t}=\beta_{0} & +\beta_{1} \text { Density }_{i, t} \\
& +\beta_{2} \text { Fragmentation }_{i, t} \\
& +\beta_{3} \text { Centralization }_{i, t} \\
& +\beta_{4} \text { Log_Tenure }_{i, t}+\beta_{5} \text { Rating }_{i, t} \\
& +\beta_{6} \text { Log_MedianPrice }_{i, t} \\
& +\beta_{7} \text { Log_NumOfProduct }_{i, t} \\
& +\beta_{8} \text { NumOfChannel }_{i, t} \\
& +\beta_{9} \text { Log_NumOfFollower }_{i, t} \\
& +\beta_{10} \text { Log_NumOfFollowee }_{i, t}+a_{i} \\
& +\varepsilon_{i} .
\end{aligned}
$$

\subsection{Results}

We run four regression models, including a model for each network variable and a regression model that includes all network variables. The regression results are shown in Table 3. As we can see from the results, the coefficients of two variables, Density, and Centralization on Log_Sales, are negative and significant. Density has a coefficient of -1.247 and is significant at the 0.1 level, and Centralization has a coefficient of -0.686 and is significant at the 0.05 level. The fragmentation index, ComponentRatio, has a coefficient of -0.059 and is not significant. The results are consistent between the regression models with

\begin{tabular}{|c|c|c|c|c|}
\hline $\begin{array}{l}\text { Log_NumOf } \\
\text { Follower }\end{array}$ & $0.430^{* * *}$ & $0.428^{* * *}$ & $0.434^{* * *}$ & $0.432^{* * *}$ \\
\hline & $(0.078)$ & $(0.078)$ & $(0.076)$ & $(0.076)$ \\
\hline \multirow[t]{2}{*}{ Density } & $-1.636^{* *}$ & & & $-1.247^{*}$ \\
\hline & $(0.834)$ & & & $(0.650)$ \\
\hline \multirow{2}{*}{$\begin{array}{l}\text { Component } \\
\text { Ratio }\end{array}$} & & -0.050 & & -0.059 \\
\hline & & $(0.069)$ & & $(0.069)$ \\
\hline \multirow{2}{*}{$\begin{array}{l}\text { Centralizati } \\
\text { on }\end{array}$} & & & $-0.774^{* *}$ & $-0.686^{* *}$ \\
\hline & & & $(0.340)$ & (0.328) \\
\hline \multirow[t]{2}{*}{ _cons } & $4.491^{* * *}$ & $4.519 * * *$ & $4.508^{* * *}$ & $4.572^{* * *}$ \\
\hline & (14.90) & (15.38) & (15.17) & (15.96) \\
\hline $\begin{array}{l}\text { Seller fixed } \\
\text { effect }\end{array}$ & Y & Y & $Y$ & $\mathrm{Y}$ \\
\hline $\begin{array}{l}\text { Time fixed } \\
\text { effect }\end{array}$ & $Y$ & $Y$ & $\mathrm{Y}$ & $\mathrm{Y}$ \\
\hline $\begin{array}{l}\text { R-square } \\
\text { Adjusted }\end{array}$ & 0.416 & 0.415 & 0.417 & 0.418 \\
\hline $\mathrm{N}$ & 14372 & 14372 & 14372 & 14372 \\
\hline \multicolumn{5}{|c|}{ Standard erors in parentheses } \\
\hline${ }^{*} \mathrm{p}<0.1 ; * *$ & 15; ** & & & \\
\hline
\end{tabular}
individual network structural variables (model 1,3) and the overall model (model 4 ). Therefore, hypotheses H1(b) and H3(b) are confirmed, and network density and centralization have significant negative impacts on sales. However, the coefficient for ComponentRatio is not significant, so $\mathrm{H} 2$ about the effect of network fragmentation on sales cannot be confirmed.

Table 3 Regression Results

\begin{tabular}{|l|l|l|l|l|}
\hline & Model1 & Model2 & Model3 & Model4 \\
\hline Tenure & $0.216^{* * *}$ & $0.217^{* * *}$ & $0.216^{* * *}$ & $0.216^{* * *}$ \\
\hline & $(0.009)$ & $(0.009)$ & $(0.009)$ & $(0.009)$ \\
\hline Rating & $-0.008^{* * *}$ & $-0.008^{* * *}$ & $-0.008^{* * *}$ & $-0.008^{* * *}$ \\
\hline & $(0.003)$ & $0.003)$ & $(0.003)$ & $(0.003)$ \\
\hline $\begin{array}{l}\text { Log_NumOf } \\
\text { Products }\end{array}$ & $0.006^{* * *}$ & $0.006^{* * *}$ & $0.006^{* * *}$ & $0.006^{* * *}$ \\
\hline & $(0.002)$ & $(0.002)$ & $(0.002)$ & $(0.002)$ \\
\hline $\begin{array}{l}\text { Log_Media } \\
\text { nPrice }\end{array}$ & -0.013 & -0.012 & -0.013 & -0.012 \\
\hline & $(0.014)$ & $(0.014)$ & $(0.014)$ & $(0.014)$ \\
\hline $\begin{array}{l}\text { Log_NumOf } \\
\text { Channel }\end{array}$ & 0.006 & 0.006 & 0.006 & 0.006 \\
\hline & $(0.006)$ & $(0.006)$ & $(0.006)$ & $(0.006)$ \\
\hline $\begin{array}{l}\text { Log_NumOf } \\
\text { Followee }\end{array}$ & -0.009 & -0.010 & -0.009 & -0.009 \\
\hline & $(0.016)$ & $(0.016)$ & $(0.016)$ & $(0.016)$ \\
\hline
\end{tabular}

The potential endogeneity may endanger the validity of the empirical results, since a user may follow a seller because the business of the seller is successful (i.e., has high sales). To address such a concern, we run regression model 4 with lagged network variables, including Log_NumOfFollowee, Log_NumOfFollower, density, ComponentRatio, and Centralization. The results remain the same. The coefficients for density and centralization are both negative and significant, while the coefficient for ComponentRatio is negative but not significant. This indicates that endogeneity does not threaten the empirical result validity.

\section{Discussions and conclusions}

This research studies the impact of structural properties of the follower ego network on the sales performance of e-commerce sellers. We hypothesize the impacts of three network structural properties: density, fragmentation, and centralization. We found negative and significant relationships between network density, network centralization and the sales performance of sellers.

This research contributes to social commerce research by studying the network structural properties of sellers' follower ego networks and their value implications. More specifically, it adds to the literature on sellers' social networks $[4,7,17,19,31]$ and advances insights on how sellers' follower networks 
affect their performance. We found that despite followers are the most important resource for a seller, some network structural properties of followers can result in liabilities for the seller. The main potential reason is that online network is transparent and traversing over the network is easy [13]. This enhances network dynamics and creates uncertainty for sellers to convert followers into buyers.

This research also contributes to the social network theory and its applications in the business field [30]. Online social networks are different from traditional social networks and understanding how online social networks work is still a nascent research area [13]. We add to this body of literature by examining the impact of online social networks in online product communities. The unique context of this kind of social network, including the proximity of the network and e-marketplace, creates dynamics for the effect of such social networks in a way that is different from those in other contexts, such as knowledgesharing networks. For example, density is often found to positively contribute to the knowledge transfer in research collaboration networks [21], but becomes a liability for sellers in the online product community.

This research offers important managerial implications to both sellers and social commerce platform providers. For sellers, building and maintaining follower networks take significant effort. However, since we found that some structural properties are negatively related to sales performance, sellers need to carefully monitor their network structure to avoid certain structural characteristics such as high centralization and high density wearing away the business value of the network. To avoid highdensity networks, sellers can diversify their channels to reach potential customers who may not be well connected. Avoiding being followed by other influencing users is a strategy that a seller can use to reduce the centralization of the ego network. Etsy offers the functionality for sellers to block unwanted followers. For social commerce platform providers, providing social intelligence such as density and centralization in the forms of descriptive statistics and network visualization can help sellers make informed decisions in building, maintaining, and leveraging their social networks in online product communities.

Several limitations of this study may inform opportunities for future research. First, we tested three network structural properties for their importance and relevance to this analysis. Future research can examine more network properties to enhance our understanding of the role of network structure and composition of the follower ego network on seller performance. Second, we study the effects of network structure in general, and future research can examine the differential effects of network structure. For example, the effect of components and fragmentation may be significant for sellers adopting different levels of diversity and differentiation in their product strategy. Third, we focus on studying the ego network. Ego networks are more feasible to study than the whole network since it only requires the information on an ego's direct connection. Despite that, studying online networks is computationally intensive due to the size of online networks. Future research can further study the whole network of online product communities and examine the value implications of network positions of sellers in the whole network. Finally, this research uses data from Etsy which has a specific structure and audience. The sellers on Etsy are microbusinesses, and the products sold are mainly handmade products. This may limit the generalizability of the research results. For example, online social networking via product interest sharing may be a less useful strategy for e-commerce sellers who sell general products. Future research can collect data from other social commerce online social networks such as the one offered by Ebay to further test the research hypotheses.

References

\section{References}

[1] Hu, T., H. Dai, and A.F. Salam, "Integrative qualities and dimensions of social commerce: Toward a unified view". Information \& Management, 2019. 56(2): p. 249-270.

[2] Curty, R.G. and P. Zhang, "Website features that gave rise to social commerce: a historical analysis". Electronic Commerce Research and Applications, 2013. 12(4): p. 260-279.

[3] Huang, Z. and M. Benyoucef, "From e-commerce to social commerce: A close look at design features". Electronic Commerce Research and Applications, 2013. 12(4): p. 246-259.

[4] Zifla, E. and S. Wattal, "Understanding ITEnabled social features in online peer-to-peer businesses for cultural goods". Journal of the Association for Information Systems, 2019. 20(5): p. 629-646.

[5] Chen, A., Y. Lu, and B. Wang, "Customers' purchase decision-making process in social commerce: A social learning perspective". International Journal of Information Management, 2017. 37(6): p. 627-638.

[6] Wang, C. and P. Zhang, "The evolution of social commerce: The people, management, technology, and information dimensions". Communications of the Association for Information Systems, 2012. 31(5): p. 1-23. 
[7] Stephen, A.T. and O. Toubia, "Deriving value from social commerce networks". Journal of marketing research, 2010. 47(2): p. 215-228.

[8] Hanneman, R.A. and M. Riddle, "Introduction to social network methods". 2005, University of California Riverside: Riverside, CA, USA.

[9] Wang, S. and F. Wang, "Network prominence in social marketplace and e-store performance: A nuanced typology and empirical evidence". Electronic Commerce Research and Applications, 2020. 43(September-October ): p. 1-12.

[10] Qu, Z., et al., "Implications of online social activities for e-tailers' business performance". European Journal of Marketing, 2013. 47(8): p. 1190-1212.

[11] Burt, R.S., "The Network Structure Of Social Capital". Research in Organizational Behavior, 2000. 22: p. 345-423.

[12] Lin, N., "Building a network theory of social capital". Connections, 1999. 22(1): p. 28-51.

[13] Kane, G.C., et al., "What's different about social media networks? A framework and research agenda". MIS quarterly, 2014. 38(1): p. 275304.

[14] Huang, N., Y.K. Hong, and G. Burtch, "Social Network Integration and User Content Generation: Evidence from Natural Experiments". Management Information Systems Quarterly, 2017. 41(4): p. 10351058.

[15] Liu, D., et al., "Friendships in online peer-topeer lending: Pipes, prisms, and relational herding". MIS Quarterly, 2015. 39(3): p. 729742.

[16] Iyengar, R., S. Han, and S. Gupta, "Do friends influence purchases in a social network?". Harvard Business School Marketing Unit Working Paper No. 09-123. , 2009: p. Available at SSRN: https://ssrn.com/abstract $=1392172$ or http://dx.doi.org/10.2139/ssrn.1392172.

[17] Susarla, A., J.-H. Oh, and Y. Tan, "Social networks and the diffusion of user-generated content: Evidence from YouTube". Information Systems Research, 2012. 23(1): p. 23-41.

[18] Hofer, M. and V. Aubert, "Perceived bridging and bonding social capital on Twitter: Differentiating between followers and followees". Computers in Human Behavior, 2013. 29(6): p. 2134-2142.

[19] Yu, X., et al., "Social networks and online store performance in emerging economies: the mediating effect of legitimacy". Electronic Markets, 2019. 29(2): p. 201-218.

[20] Perry, B.L., B.A. Pescosolido, and S.P. Borgatti, Egocentric network analysis: Foundations, methods, and models. Vol. 44. 2018: Cambridge university press.

[21] Gilsing, V., et al., "Network embeddedness and the exploration of novel technologies: Technological distance, betweenness centrality and density". Research Policy, 2008. 37(10): p. 1717-1731.

[22] Soh, P.-H., "Network patterns and competitive advantage before the emergence of a dominant design". Strategic Management Journal, 2010. 31(4): p. 438-461.

[23] Kreiser, P.M., "Entrepreneurial orientation and organizational learning: The impact of network range and network closure ". Entrepreneurship Theory and Practice 2011. 35(5): p. 1025-1050.

[24] Carnovale, S. and S. Yeniyurt, "The role of ego network structure in facilitating ego network innovations". Journal of Supply Chain Management, 2015. 51(2): p. 22-46.

[25] Coleman, J.S., "Social capital in the creation of human capital". American journal of sociology, 1988. 94: p. S95-S120.

[26] Borgatti, S.P., M.G. Everett, and J.C. Johnson, Analyzing social networks. 2018: Sage.

[27] Johnson, S.L., S. Faraj, and S. Kudaravalli, "Emergence of power laws in online communities: The role of social mechanisms and preferential attachment". MIS Quarterly, 2014. 38(3): p. 795-808.

[28] Yan, B., et al., "The Paradox of Interaction: Communication Network Centralization, Shared Task Experience, and the Wisdom of Crowds in Online Crowdsourcing Communities". Communication Research, 2020: p. 1-23.

[29] Becker, J., D. Brackbill, and D. Centola, "Network dynamics of social influence in the wisdom of crowds". Proceedings of the national academy of sciences, 2017. 114(26): p. E5070-E5076.

[30] Wasserman, S. and K. Faust, Social network analysis: Methods and applications. Vol. 8. 1994, Cambridge, UK: Cambridge university press.

[31] Wang, Y., et al., "Store survival in online marketplace: An empirical investigation". Decision Support Systems, 2013. 56(December): p. 482-493. 